\title{
International photonics training: a case study
}

Dan Sporea, Nicholas Massa, Judith Donnelly, Fenna Hanes

Dan Sporea, Nicholas Massa, Judith F. Donnelly, Fenna Hanes, "International photonics training: a case study," Proc. SPIE 9665, Tenth International Topical Meeting on Education and Training in Optics and Photonics, 966500 (3 June 2007); doi: 10.1117/12.2207315

SDIE Event: Tenth International Topical Meeting on Education and Training in Optics and Photonics, 2007, Ottawa, Ontario, Canada 


\title{
International Photonics Training: a Case Study
}

\author{
Dan Sporea \\ National Institute for Laser, Plasma and Radiation Physics, Center for Science Education and Training (CSET), \\ 409 Atomistilor St., Magurele, RO-077125, Romania, (40)745759545, (4021)4574243(fax), dan.sporea@inflpr.ro
}

\author{
Nicholas Massa \\ Central Connecticut State University, 1615 Stanley Street, New Britain, CT 06050 \\ Judith Donnelly \\ Three Rivers Community College, 7 Mahan Drive, Norwich, CT 06030 \\ Fenna Hanes \\ New England Board of Higher Education, 45 Temple Place, Boston, MA 02111
}

\begin{abstract}
From 2004, the Center for Science Education and Training (CSET) participated to the European Unionfunded educational network "Hands-on Science". The aim of the Romanian team was to transform teachers and students from end-users of educational aids to active designers and developers of instructional materials. Several science fields were identified, including photonics. The team at CSET is now focusing on: lasers and their applications, optical fiber communications, solar energy as a sustainable source, and the use of optical spectroscopy in physics and chemistry. CSET initiated an international collaboration with the New England Board of Higher Education (NEBHE) in Boston, Mass., when the Center enrolled an experienced Romanian high school science teacher in a twelve-week "Introduction to Photonics" laboratory-based professional development course. The course was developed by NEBHE through an Advanced Technological Education (ATE) program grant from National Science Foundation and is designed for high school and community college educators from both science and technology instructional areas. The paper reports the experience of this international participation which was made possible since the course is delivered via the Internet by Three Rivers Community College, Norwich, Conn. Its impact on photonics education in Romania and the USA is analyzed, as the participant teacher shares her experiences with teachers and faculty in the "Introduction to Photonics" course and with those enrolled into the Romanian "Hands-on-Science" program.
\end{abstract}

\section{Introduction}

In the last five years, Europe designed a coherent strategy and adopted several programs aiming to the accelerated development of education at all levels (pre-university, university, vocational training, lifelong learning), and focusing on the implementation at continental scale of the new, knowledge-based society, ready to be a major competitor on the global labour market. During the Lisbon meeting (March 2002), Heads of State and Government of the European Union established a new strategy for Europe's development. They aimed to make the European Union "the most dynamic and competitive knowledge-based economy in the world" by 2010. This set of ambitious reforms at the national and European level will be reached by establishing an effective internal market, by boosting research and innovation and by improving education among other measures [1], [2]. The role of education within the Lisbon strategy is pointed out by the conclusions of a report for a European Council meeting held in Brussels (February 2002) as "the essential role to be played by education and training in improving the level of qualifications of the population. It seeks to respond not only to the challenges issued by the Lisbon European Council in March 2002 .... but also to the wider needs of citizens and society. Education and training are thus a basic priority area in the Lisbon strategy" [3]. Within this frame, the quality of the education and training in Europe by 2010 will be proved by the fact that "Europe will be recognized as a world-wide reference for the quality and relevance of its education and training systems and institutions". The implementation of the Lisbon Agenda in the field of education and its main direction of action are defined in the programme "Education and Training 2010" [4]. The official documents recognize that an adequate supply of scientists is crucial for a knowledge-based economy, and for this reason, the Council has set two objectives: "to bring about an increase of at least $15 \%$ in the number of graduates in these fields by 2010 and at the same time to redress the imbalance between women and men" [5].

Tenth International Topical Meeting on Education and Training in Optics and Photonics, edited by Marc Nantel, Proc. of SPIE Vol. 9665, 966500 - @ 2007 SPIE, OSA, IEEE, ICO doi: $10.1117 / 12.2207315$ 
An European Commission document issued in 2002 indicates clearly some paths to follow in the field of education along with some precise targets [6]:

- "Europe must do more to encourage children and young people to take a greater interest in science and mathematics, and to ensure that those already working in scientific and research fields find their careers, prospects and rewards sufficiently satisfactory to keep them there. Motivating more young people to choose studies and careers in the scientific and technical fields in a short and medium term perspective";

- "By 2010, the percentage of low-achieving 15 year-olds in reading, mathematical and scientific literacy will be at least halved in each Member State, compared to the year 2000";

- "By 2010, the EU-average level of participation in lifelong learning should be at least $15 \%$ of the adult working age population (25-64 age group) and in no country should it be lower than 10\%”.

The 2003 Working Group on "Increasing Participation in Math, Science and Technology" (MST) made five recommendations for schools to follow in teaching science and technologies [7]: "the teaching of mathematics, science and technology should be an entitlement for all children from the early stages of education and should be mandatory at all levels; more effective and attractive teaching methods should be introduced in mathematics, scientific and technical disciplines at both primary and secondary level, in particular by linking learning to real-life experiences, working life and society and by combining classroom-based teaching with extra-curricular activities; the professional profile and practice of MST teachers should be enhanced not only by providing them with opportunities and incentives for updating their knowledge of both content and didactics of MST through the provision of effective initial and in-service training and by improving teaching resources, but also through the provision of incentives and special measures to ensure their long-term commitment to the teaching profession; measures involving teaching methods, pedagogical tools and assessment measures for special needs groups such as high and low achievers and pupils from ethnic minority backgrounds should be addressed along with measures to address gender-specific attitudes to mathematics, science and technology; strong and effective partnerships between schools, universities, research institutions, enterprises, parents and other players should be strongly supported and encouraged at all levels, both to improve the quality and attractiveness of teaching and to effectively prepare young people for working life and active citizenship."

In this context, the National Institute for Laser, Plasma and Radiation Physics' Center for Science Education and Training - CSET, near Bucharest (Romania), started two national level educational projects. The projects are: the Romanian part of the European Comenius network "Hands-on Science" [8], and the Romanian project "Science Education and Training in a Knowledge-Based Society - SET 2010" [9]. The paper addresses the methods used and presents some of the achievements in the frame of the two projects. CSET initiated an international collaboration with the New England Board of Higher Education (NEBHE) in Boston, Mass., USA when the Center enrolled an experienced Romanian high school science teacher in a twelve-week "Introduction to Photonics" laboratory-based professional development course. The course was developed by NEBHE through an ATE grant from the National Science Foundation and is designed for high school and community college educators from both science and technology instructional areas. This collaborative work constitutes the case study for our paper.

\section{Brief history and the background}

The two above mentioned projects support in a complementary manner science education in schools, at all levels, in various fields: physics, chemistry, biology, environmental issues, human physiology, consumer protection, etc. Our efforts are focused on building a bridge between academia and research institutes on one side and the pre-university teaching infrastructures on the other side.

The main themes of the Comenius network are:

- $\quad$ to invite local communities and authorities to be involved in debates on science education;

- to promote and deliver training courses for school teachers and educators in different languages and countries on science related curricula;

- $\quad$ to promote Hands-on-Science contests and fairs at national and EU level;

- $\quad$ to promote science clubs activities in schools;

- $\quad$ to develop and disseminate new ICT and multimedia education materials;

- to create a network of teachers interested in MST subjects to serve as possible disseminators;

- to organize international conferences and thematic workshops on this subject. 
As it concerns the national project "SET 2010" its target is more general: the science education in the context of lifelong learning and scientific literacy. Within this project framework the major goals of our activities are:

- to promote European best practices and to establish a partnership between the Romanian teams and advanced networks in Europe, in the field of education, for the technical and scientific knowledge and lifelong learning;

- $\quad$ to develop a regional network (in the Balkan area and in East and Central Europe) aimed to increase the quality of science teaching at the pre-university level;

- to develop a collaboration with the "Hands-on Science" European network using real and virtual experimentation;

- $\quad$ to support European level dissemination of key results regarding science education in Romanian schools.

In designing the working plan for Romanian participation in the projects, we focused on several options that can bring maximum benefit to both the project and the country, on its way to EU integration:

a. to build strategic partnerships with organizations and companies which can assist us to run the project, either through direct financial support or by associating the project name with their image;

b. $\quad$ to support the inclusion of virtual instrumentation programming teaching in high schools;

c. to assist high schools in developing virtual experiments;

d. to encourage high school teachers to train students in developing their own experimental set-ups and training aids;

e. $\quad$ to prepare teaching materials in electronic and multimedia format;

f. to facilitate access to experiment-based teaching to less favoured groups;

g. to disseminate project results though lectures, conferences, communication sessions.

The major directions of action for the next 2-3 years are: the use of IT in developing and running experiments in school labs, 3D graphics and animation as a teaching aid, education for a sustainable development, the training of school students in modern electronics and robot programming.

Since the "Photonics21" European Technology Platform and the "Strategic Research Agenda in Photonics" [10] were launched in April 2006, interest in photonics education increased. The Agenda states "Photonics differs from the fundamental subjects of physics, chemistry, biology and mathematics, in that it is highly interdisciplinary. In most member states of Europe today, 1st and 2nd level education (primary and secondary school) deals only with the core sciences, not interdisciplinary ones. This however offers a great opportunity for photonics, since it is ubiquitous and all pervasive presence means that it is part of all the basic sciences, an awareness of photonics can be introduced by appropriate outreach activities in schools. We need to "spread the word" about photonics, both in schools and to the general public." For this reason, we started to focus our efforts towards education in modern optics and photonics.

As in the case of other educational fields in which we are active, in photonics education we combine different approaches:

- $\quad$ demo and inquiry-based sessions, when students either present to their fellows a subject related to optics and photonics in order to complete the information they receive during school courses, or have direct investigations on a specific topic;

- $\quad$ organization of temporal exhibitions;

- $\quad$ science club activities, where students demonstrate their abilities to develop simple training aids, set-up their own experiments or build quite complex optical instruments to be used in future science projects;

- $\quad$ organization of science fairs and students' contests;

- development of advanced experiments that demonstrate links between photonics and other natural sciences;

- visits at the Institute through an “open doors” programme;

- $\quad$ institute support in preparing school textbooks;

- $\quad$ organization of nation-wide events focusing on optics/ photonics;

- $\quad$ participation in international conferences/ exhibitions/ workshop.

Generally, demo sessions are run for half a day during weekends. Participants are teachers and students from the same neighbourhood. During these events the mean form of communication is PowerPoint presentations prepared by students after ample documentation using the Internet. In some situations dedicated experiments are also shown to the audience. Figure $1 \boldsymbol{a}$ presents the life dissection of a bull's eye. The biology teacher explains the role that each constituent part of the visual system plays in forming the image (Figure $1 \boldsymbol{b}$ ). In some cases, a small exhibition that focuses on a specific subject, accompanies the event. In Figure $1 \boldsymbol{c}$ students are introduced to educational instruments used to teach optics. 


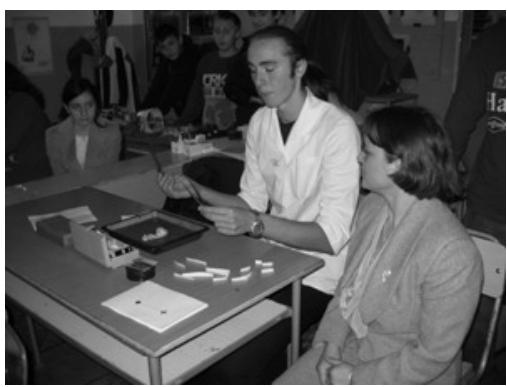

a

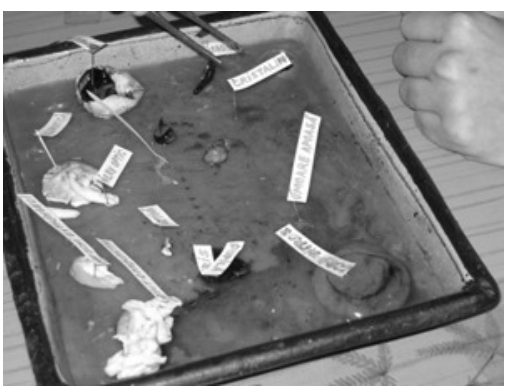

b

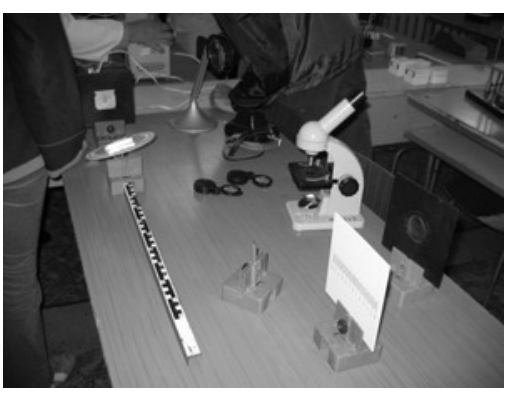

C

Figure 1. Life demo of the structure and functioning of the visual system in the animal kingdom ( $\boldsymbol{a}$ and $\boldsymbol{b})$; exhibition of instruments for teaching optics $(\boldsymbol{c})$ - photos from D. Sporea's collection.

Partner schools in our projects organize science club activities in the afternoons. Here students are taught to develop their own experimental set-ups and instruments, which are also used during class work or to start some small research projects. This approach is helpful since most of the ordinary schools lack the necessary teaching aids. Younger students are first introduced to simple experimental schemes that use light sources (Figure $2 \boldsymbol{a}$ ) or to basic optics (Figure $2 \boldsymbol{b}$ ).

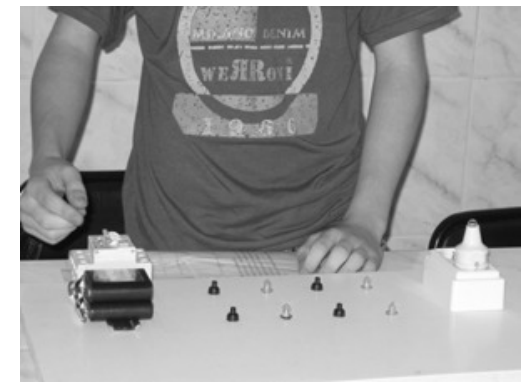

a

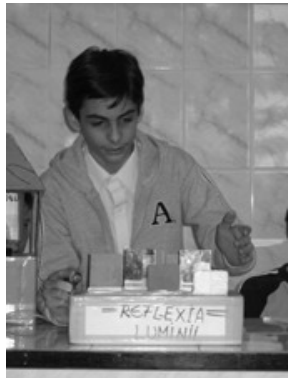

$\mathrm{b}$

Figure 2. An eight years old student playing with optoelectronic circuits (a); a simple experiment in optics built by a 10 year old student $(\boldsymbol{b})$ - photos from D. Sporea's collection.

Students $15-17$ years old are assisted by their teachers to develop more sophisticated experiments. Figure $3 \boldsymbol{a}$ shows the award winning team of a theoretical high school in Bucharest with the telescope they built to participate in a science club on astronomy. Romanian students took part with their experiments to international science projects. Figure $3 \boldsymbol{b}$ shows the instrument used to evaluate the solar constant during an international investigation run by students. By coupling a webcam to a microscope, a PC assisted image processing tool was developed to study plants and small insects (Figure $3 \boldsymbol{c}$ ).

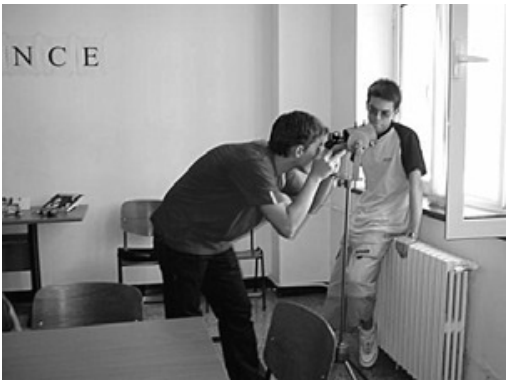

a

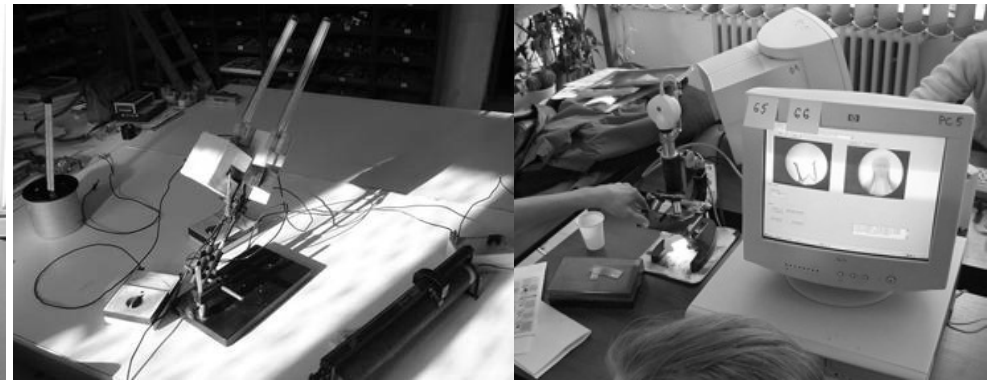

b c

Figure 3. High school students operating the telescope they developed (a); set-up to measure the solar constant (b); a complex PC-based image processing set-up used to study biological specimens (c) - photos from D. Sporea's collection. 
We use different means to introduce students to optics from an early age. One example is an exhibition we organized that focused on light and colors which used photos and drawings done by the students. In most of the cases students brought their own perception and understanding of the subject. In Figure $4 \boldsymbol{a}$ the author intended to offer an overview of the illustration of light in ancient times, while the drawing in Figures $4 \boldsymbol{b}$ summarizes a short history of scientific discoveries in optics. In some artistic products imagination plays the major role. The rainbow is perceived as being the light spread by a diamond embedded into a hill (Figure $5 \boldsymbol{a}$ ). The author of the drawing in Figure $5 \boldsymbol{b}$ also proved to be an active militant ecologist - the light bulb includes a windmill device, under the title "Towards a greener light".

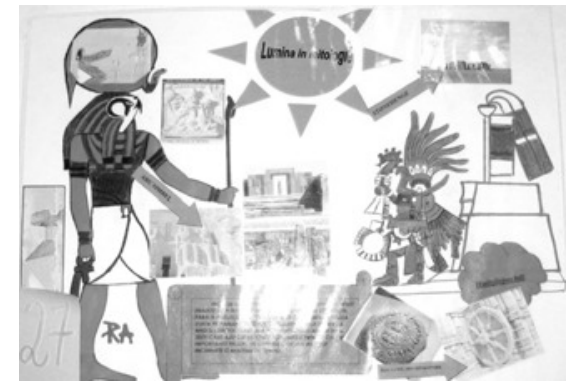

a

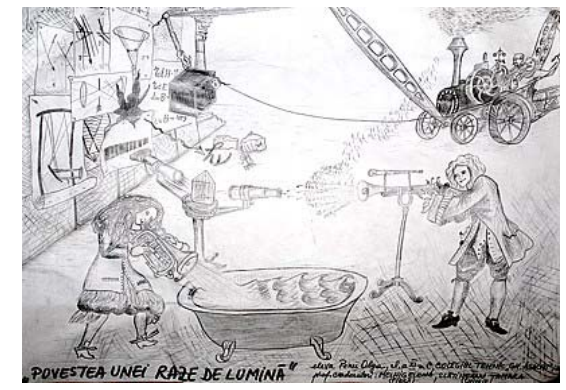

b

Figure 4. Light as it was illustrated in ancient times (a); a brief history of optics discoveries $(\boldsymbol{b})$ - photos from D. Sporea's collection.

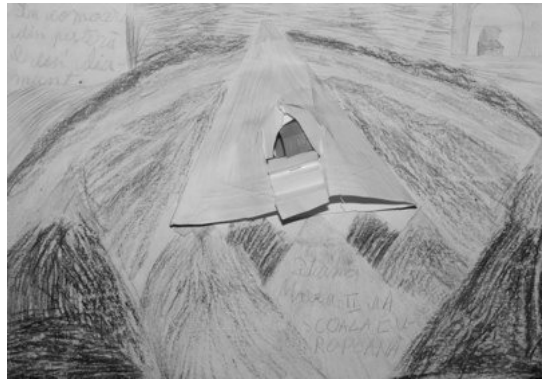

a

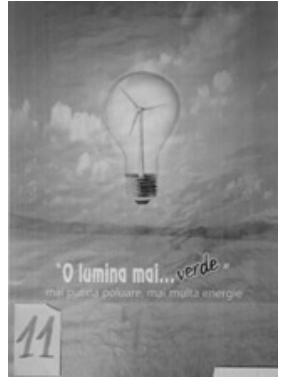

b

Figure 5. Rainbow generated by the diamond buried into a hill (a); “Towards a greener light” (b) - photos from D. Sporea's collection.

In order to call the general public's attention to the important partiture this form of energy (Light) plays in our life, this March, we organized a nation-wide symposium on this subject. The programme included real and virtual experiments, scientific presentation delivered either by scientists (a lecture on the Sun presented by a researcher at the National Institute of Astronomy, talks on lasers, holography, optical communications) or by groups of teachers and students. As the event was open to all types of schools (theoretical, vocational, school of arts) the contributions (over 160 with more that 260 authors) included not only science and technology related subjects but also essays, poetry, and drama. To illustrate the fascination of this event, it is worth mentioning some interesting discussions that took place on the place of mirrors in the lyrics of the most renown Romanian poet, the opposition between light and shadow crossing four centuries of painting, and a very interesting artistic interpretation of a Sun eclipse (Figure $6 \boldsymbol{a}$ ). There was also an interesting tale, written and played by some 16 years old students, on modern lighting (Figure 6 $\boldsymbol{b}$ ). The response to this event was so strong that one high school dedicated a full issue of its school magazine to "Light" and another one designed a wall calendar.

We started a programme in two high schools in Bucharest to assist with teaching photonics by providing optics and optical communication training kits, a small footprint spectrometer and different sensors. Until now, they organized science club activities with these kits (Figure $7 \boldsymbol{a}$ ) and set up some experiments by connecting the sensors to a PC with an USB data acquisition board from National Instruments. The graphical program LabVIEW was used to collect and to process data (Figure $7 \boldsymbol{b}$ ). 


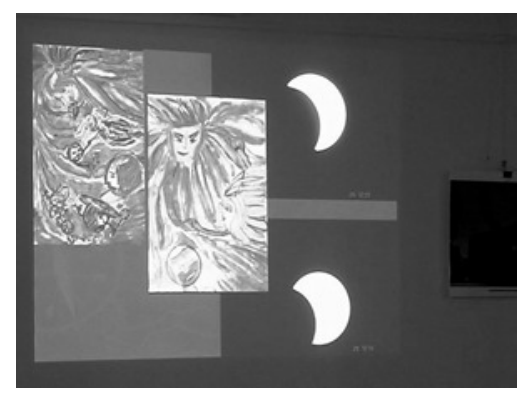

a

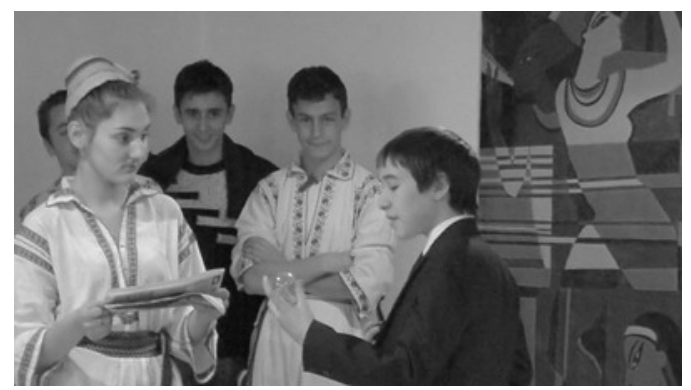

b

Figure 6. Scientific facts facing an artistic interpretation on a Sun eclipse (a); "Lighting" drama on a scientific subject $(\boldsymbol{b})$ - photos from D. Sporea's collection.

Projects results were disseminated at national and international conferences and workshops [11 - 14] and a booth was organized in Brussels, at the invitation of the European Commission, during the Conference "Communicating European Research".

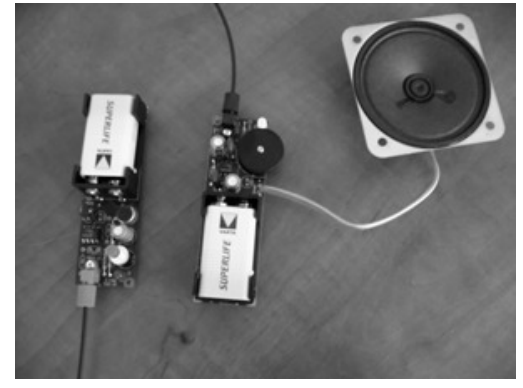

a

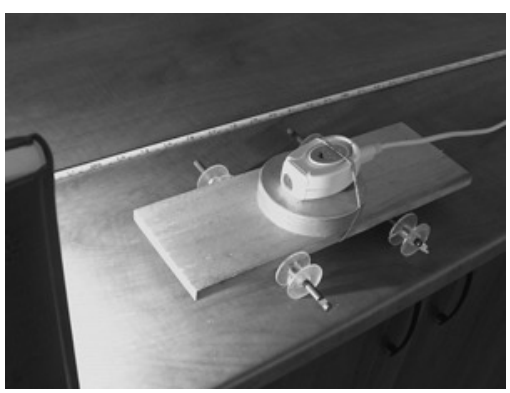

C

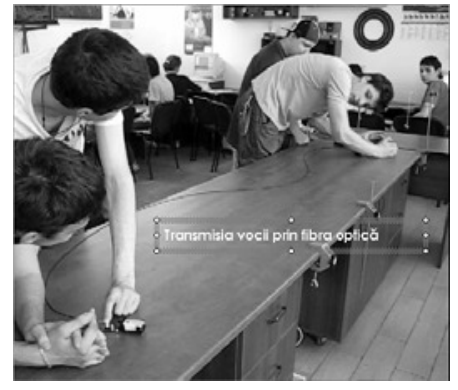

$\mathrm{b}$

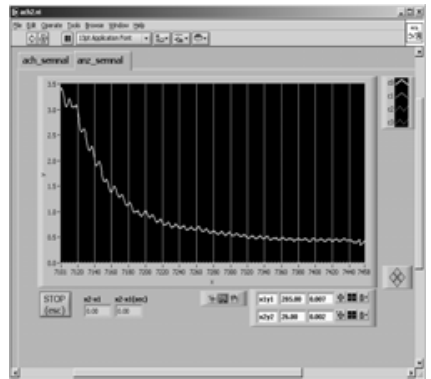

d

Figure 7. Photonics related experiments at Theoretical High School "Grigore Moisil" in Bucharest: Voice communication using an optical fiber link ( $\boldsymbol{a}$ and $\boldsymbol{b}$ ); experiment with optical sensors controlled in LabVIEW ( $\boldsymbol{c}$ and d) - courtesy of high school teachers Mihaela Garabet and I. Neacsu.

\section{The training course on photonics - the case study}

Coming back to the European Union's policy in education for the next decade we have noticed several points of interest: the need to address science education through extra curricular teaching programmes, the importance of hands-on training, the development of lifelong leaning strategies to be applied, and the stringent requirement to assist teachers in developing new methods of teaching applied sciences, sciences closely linked to everyday life. Through our efforts, we addressed these issues to some extent by using IT in the lab. As it concerns photonics, the major drawback is related to the lack of the appropriate support and means to further educate teachers in this subject. Teacher training and lifelong learning must be part of our strategy to support science education in our schools. As the funds to develop schools' educational infrastructure are limited (laboratory equipment, training aids, and kits to 
set-up experiments), it is quite difficult to improve science education. In any case, we were open to any opportunity to overcome this situation.

By mid-October 2006 D. Sporea, the national coordinator of the "Hands-on Science - Romania” network, learned about the PHOTON2 photonics education project offered in the States by the New England Board for Higher Education in cooperation with Three Rivers Community College (TRCC). We contacted the project Principal Investigator (PI) Fenna Hanes and we agreed to collaborate.

PHOTON2 is a three-year curriculum and professional development and laboratory improvement project of the New England Board of Higher Education. The project, funded by the Advanced Technological Education (ATE) program of the National Science Foundation (NSF) began in September 2003 and completed at the end of August 2006. A one-year "no-cost" extension is in progress to complete all activities and reports by summer 2007.

The goal of the PHOTON2 project is to:

1. Adapt the successful PHOTON (September 2000 - 2003) instructional materials, laboratory equipment kit and "alliance" model to a web-based distance-learning environment.

2. Disseminate PHOTON instructional materials, laboratory equipment kit and "alliance" model, (the inclusion of teachers/faculty and career counselors from consortia of secondary and postsecondary institutions) to a national audience.

3. Evaluate the effectiveness of a web-based distance-learning program that methodically applies adult collaborative learning principles for future replication.

PHOTON2 utilizes 21st century web-based technology to deliver a one-semester web-based professional development course "Introduction to Photonics Technology." The course instructional materials had been implemented and field-tested by teachers and faculty in middle, secondary and postsecondary institutions in New England during the previous Project PHOTON.

Phase 1 of the project included a series of two-day regional introductory workshops. The purpose of the 2-day workshops was to introduce the educators to the online learning environment, course material and laboratory equipment to establish a professional rapport with the PHOTON2 instructional team and other participants and to assess the learning environment at each regional site. Each of the two-day workshops included a tour of a local photonics company in an effort to solicit industry participation in the program and to provide career and guidance counselors with career awareness in the photonics field. A partial list of companies included, Cisco Systems, Veeco Instruments, Photomachining, Coherent Laser, Trex Enterprises, and several others. Collaborations established with photonics companies and industry associations (OSA and SPIE) in Project PHOTON were continued and expanded from a New England to a national focus.

In Phase 2 the PIs developed the PHOTON2 web-based distance-learning course, "Introduction to Photonics." Under the leadership of Co-PI Judith Donnelly, TRCC in Norwich, Conn. delivered the course through the Connecticut Distance Learning Consortium.

Each participating institution was provided with a complete set (15 chapters) of field-tested optics and photonics course notes and a $\$ 4000$ custom industry quality optics lab kit. Half the cost of the kit was provided by the grant, the schools or a school partner matched the other half. The kit includes a field-tested lab manual with 25 laboratory experiments ranging from simple demonstrations of refraction and diffraction to building and aligning a Michelson interferometer. The kit is accompanied by two a set of CD-ROM videos in which PHOTON2 instructors provide step-by-step instructions for performing each experiment. A set of 13 introductory-level Explorations completes the instructional materials. Throughout the project, the project instructional team provided technical assistance through an active industry mentored listserv, via email, phone and site visits.

In Spring 2004, Cohort I, the first of two cohorts, consisting of five regional "alliances” each comprised of high school teachers, community college faculty, career and guidance counselors, and industry representatives was formed. Each of the five alliances, representing institutions from New England (Connecticut, Massachusetts), California, Arizona, Texas, and Pennsylvania, participated in a two-day face-to-face regional introductory workshop.

Research has shown that although there are many positive aspects to distance learning, there are challenging pedagogical aspects to achieving successful learning experience. PHOTON2 addressed these challenges by applying adult learning principles in the design and development of the new web-course.

Under the direction of Co-PI Nicholas Massa and Marijke Kehrhahn, research was conducted at the end of the fall 2004 semester to better understand the relationship between learner interaction, self-regulatory development, critical thinking skills, and learning outcomes and to guide the implementation of the PHOTON2 web-based course for Cohort 2.

Based on preliminary findings from Cohort 1, several changes were made to the PHOTON2 web-course. First, the 2-day regional introductory workshops were held closer in time to the beginning of the course (within 4-8 
weeks) so that participants would not lose their momentum and motivation for taking the course nor their skill at navigating the course. Second, the course was opened for participation one week before the actual start date for the course so that participants could log on and introduce themselves to the larger group in an effort to increase the amount of social rapport. Third, the scope of material to be covered during the semester was reduced.

By reducing the amount of material covered, more time was able to be spent on core concepts with the hope of fostering deeper learning, and as a result, increase the likelihood that the material would (or could) be applied in participants' classrooms. Last, and most important, the format of the PHOTON2 web-based course was modified from a traditional instructor-centered format in which all course activities and discussions are centered on the instructor, to a learner-centered approach, where the role of the instructor shifts from leader to facilitator. The purpose for this change in format was to increase the level of learner-to-learner interaction in an effort to create a more collaborative learning environment where learners would work together to construct knowledge and ideas through interactions and responses from others.

Of the 23 teachers who started the course for Cohort I, one withdrew for personal reasons and four changed to audit status because of situational constraints. Of the remaining 18 participants, complete data sets were obtained for 15 participants.

During spring semester 2005, Project PHOTON2 delivered the second offering of the "Introduction to Photonics” professional development course via distance learning to Cohort 2. Cohort 2 participants also attended introductory workshops similar to those attended by Cohort 1. Participants formed into four alliances of high schools and colleges from New England (Connecticut, Maine, New Hampshire, Vermont); California; Tennessee and Alabama; and Hawaii.

Of the 28 teachers and faculty who started the course for Cohort 2, four withdrew for personal reasons within the first two week of the course and three changed to audit status because of situational constraint, and three did not complete the course for other reasons. Of the remaining 18 participants, complete data sets were obtained for 13 participants for analysis. A comprehensive paper, The PHOTON2 Web-Based Professional Development Model: A Year in Review, that describes the research component of Project PHOTON2, was presented at ETOP 2005 by PHOTON2 PI Nicholas Massa and can be viewed on the NEBHE web site, www.nebhe.org/photon2.

Requests for offering the distance learning course surfaced as the project progressed and word of the course and the PHOTON2 materials spread. Consequently, outreach was begun in fall 2006 to offer a class in spring 2007. This time the course was opened up to educators outside of the PHOTON2 cohort.

NEBHE agreed to enrol one Romanian school teacher in the twelve week "Introduction to Photonics" professional development course offered in spring 2007. This decision to participate was both a big chance and a great challenge for the Romanian teacher selected to learn about a very modern field from an experienced team. The course was delivered on-line, hence the costs were diminished. Participation in this course was a challenge as he/ she had to confront cultural and language barriers, a shifted learning programme and lack of the appropriate instructional aids.

Another challenge was for the Romanian network coordinator to find the appropriate person to take advantage of this experience. After several trials and discussions Mrs. Elena Vladescu was selected for the course, as she has a good command of English, is a very active person within CSET network and is very dedicated to hands-on science [15]. Another reason for selecting her was the fact that we wanted to encourage teachers from small communities to join the stream. She teaches at a vocational school in a small town $200 \mathrm{~km}$ from Bucharest. By appointing her to this task, we also send a signal to her fellow teachers spread across the country that they are not abandoned and that they too have a future in the educational system where there is starting to be a shortage of qualified and dedicated persons in the field of pre-university education in Romania.

The Romanian teacher participating in this course also lacked the technical equipment required by the course curriculum (the advanced PHOTON kit for optics). We were only able to assist her with the OSA Discovery kit for basic optic teaching. Nevertheless, she managed to use this kit extensively and produced her own built experiments.

During the course she delivered demo sessions to her class, using the new skills she acquired.

As the course progressed, we all realized the great benefit it was bringing to the Romanian education community: a completely new (for us) approach on science teaching emerged - the focus on experiments and direct hands-on involvement of the trainees. For us, it was a surprise as the Romania system is traditionally more linked to the theoretical approach in teaching science. Another big surprise for the Romanian participant to the course was the testing part of the course since she was taking the course for credit. She passed all the examination with the highest marks, despite language barriers, which can impinge on the perception of questions to be solved. In the mean time, she proved to be very active and imaginative in dealing with the tests and in designing her own experiments.

We disseminated the course results and Elena's training experience through a 20 minutes presentation she gave at our national educational symposium on "Light”. Her presentation had a big impact as the audience was tuned to 
this subject, and because we succeeded in bringing a large number of participants to her presentation. The attendees were very interested in the subject and she spent time during the break explaining the details of the experiments she had run. Encouraged by this interest, we decided to add the presentation of all the experiments she developed during her training as well as additional tips and assistance to Elena's teaching web site.

For the Romanian site, the experience with this internationally delivered course underlined several points:

- $\quad$ The course was not an easy one, but it has no extremely difficult parts. It was evaluated as not an easy one, as far as it is quite demanding and you have to manage very carefully your resources and your time. The course is quite demanding, there are a lot of things you have to learn and you need to spend a lot of time studying.

- $\quad$ The overall organization of the course was excellent; it operates as a clockwork mechanism.

- The novelty of teaching optics in schools appeared to us in connection to the practical approach of the course. In Romania, by tradition and because of the lack of funds, physics and chemistry teaching has a pronounced theoretical approach. The way optics (and more generally science) is introduced in classroom in the States is focused on the interest the student has on the subject in relation to his/her future job opportunities and the labour market request.

- In the States, the basic curricula is quite the same as in Romania, but it is not so packed.

- $\quad$ This novel approach pushed Elena further in designing her lesson plan. In any case, this experience during the course she took change the way she is approaching optics teaching. She started to include more experiments, simple to built ones, using trivial materials and the OSA Discovery kit. Her students became more interested into optics and assisted her during the experiments. This "cooperation" opens channels also for discussion and enquiries from the students' part.

- We were also impressed by the very friendly connection established with tutors. In another way, the course made possible for the Romanian teacher to establish a close contact with her tutors, and she was impressed by the possibility to discuss openly subjects of common concern.

- A little bit of contrast appear as Elena's fellow teachers attending the course were not as communicative with her as expected. May be some time there is a lack of interest from their part even towards the course.

- The biggest technical difficulty was related to the horary shift fact which affected the Romanian teacher participation to chat activities ( 7 hours shift in relation to the tutors and up to 12 hours with respect to some attendees from Hawaii). Nevertheless, special chat sessions were organized on Saturdays, so she can participate, too. As Elena misses an Internet connection at home she had to spend quite a lot of time at school, at the library or in an Internet Cafe.

- Another drawback in relation to her participation concerns the limited technical means she has for the experiments. Elena dreams to have access to various light sources, a spectrometer, an interferometer, unlimited around the clock Internet access, and may others. She realized to acute need for technical support in Romanian schools.

- $\quad$ Elena managed quite well in handling lessons in English and proved her language skills during all the tests, but she still faced difficulties when slang and jargon terms are used. In such situation both tutors and fellow students offered assistance.

- The course was also a proof on the consistency of science teaching in Romanian universities. From this point of view, her background from the university helped her a lot. In fact, in Romania ALL science teachers in high school have a master degree in the science they are teaching.

- The communication level with all the tutors was excellent and very supportive. In spite of the fact the course is based on a collaborative approach very few attendees established a close link with her. This fact it is not so common for Romania, where generally people are very open and communicative.

- $\quad$ Elena dedicated most of her time to this course, as it was a demanding and unusual activity for her. She took all the challenges (without any complex or bias) and done her best to be involved in all activities. She even contributed to some improvements in the experiments they were running.

\section{Conclusions}

The a Romanian teacher's participation in NEHBE's "Introduction to Photonics" on-line course, primarily designed for the American "market", proved to be a very helpful experience for the Romanian "Hands-on Science" network community. It underlined one more time our limits in training teachers through in-service training programmes. This experience also demonstrated the acute need to change teaching methods in Romania, by 
accentuating the practical aspects and the hands-on methods. In the mean time, we have to change our old way of science education as our students will have to face a much higher competition in a global job market. Following this experience, we plan to continue cooperation with NEBHE, and to develop two to three small centers, at a national level, with the appropriate teaching aids ready to replicate, at least partially, the teaching methods Elena has learned.

At the international level, outreach on engineering education listservs, that reach educators across the globe, became reality and the rest is history to be written.

\section{Acknowledgements}

Dan Sporea would like to acknowledge the financial support of the European Union to develop, in the frame of the Comenius project "Hands-on Science" (Project $\mathrm{n}^{\circ}$. 110157-CP-1-2003-1-PT-COMENIUS-C3), the national educational network "Hands-on Science - Romania", as well as the financial support of the Romanian Authority for Scientific Research to set-up and to run the Center for Science Education and Training (contact No. 58/ 2006 Science Education and Training for a Knowledge-Based Society).

\section{References}

[1] http://europa.eu.int/growthandjobs/index_en.htm.

[2] http://europa.eu.int/comm/education/policies/2010/et_2010_en.html.

[3] Pilar del Castillo Vera and Juan Carlos Aparicio Pèrez, Report for the 2408th Council meeting - Education and Youth Affairs, Brussels, 14 February 2002.

[4] Commission of the European Communities, Communication from the Commission, Education \& Training 2010. The Success of the Lisbon Strategy Hinges on Urgent Reforms, Brussels, 11 November 2003.

[5] Commission of the European Communities, Commission Staff Working Paper. Progress towards the Lisbon Objectives in Education and Training, Brussels, 22 March 2005.

[6] Commission of the European Communities, Communication from the Commission, European benchmarks in education and training: followup to the Lisbon European Council, Brussels, 20 November 2002.

[7] European Commission, Implementation of the Education and Training 2010 Work Programme, Progress Report, December 2004.

[8] www.hsci.info.

[9] http://education.inflpr.ro

[10]www.Photonics21.org, Towards a bright future for Europe, Strategic Research Agenda in Photonics.

[11]Dan Sporea si Adelina Sporea , “The Romanian Experience within the Comenius Project "Hands-on Science” in "Science Education: Best Practices of Research Training for Students under 21”, editori Peter Csermely, Tamas Korcsmaros si Leon Lederman, NATO Science Series, IOS Press, Amsterdam, 2005.

[12] Manuel Costa, Dan Sporea, Clementina Timus, “Optics Education in the frame of the Comenius "Hands on Science” project”, ETOP 2005 Conference on Education and Training in Optics and Photonics, October 23-27, 2005, Marseille, France.

[13]Dan Sporea, "Extra curricular photonics education in Romanian high schools", Proceedings of the International Conference "Micro- to Nano Photonics”- ROMOPTO 2006, August 28-31 2006, Sibiu, Romania.

[14]Dan Sporea, Adelina Sporea, “ The role of science clubs and science fairs in science education in schools”, NATO-UNESCO Advanced Research Workshop „Science Education: Talent Recruitment and Public Understanding”, 20 - 22 October 2006, Balatonfüred, Hungary, accepted for publication in NATO Science Series.

[15] http://www.geocities.com/physicsexperiments. 